\title{
Development of Mycelium Materials Incubating Pleurotus Ostreatus Fungi With Different Substrates Composed of Poplar Sawdust and Cottonseed Hull
}

\section{Rong Ding}

College of Food Science and Technology, Shanghai Ocean University, Shanghai, 201306, China

\section{Xinyu Yang}

College of Food Science and Technology, Shanghai Ocean University, Shanghai, 201306, China

\section{Liucheng Peng}

College of Food Science and Technology, Shanghai Ocean University, Shanghai, 201306, China

Jing Xie

College of Food Science and Technology, Shanghai Ocean University, Shanghai, 201306, China.

Shanghai Professional Technology Service Platform on Cold Chain Equipment Performance and Energy Saving, Evaluation, Shanghai, 201306, China. Shanghai Engineering R

Chenwei Chen ( $\nabla$ cwchen@shou.edu.cn )

Shanghai Ocean University

\section{Research}

Keywords: Mycelium, Mycelium material, Pleurotus ostreatus fungi, substrate

Posted Date: October 18th, 2021

DOl: https://doi.org/10.21203/rs.3.rs-960342/v1

License: (c) (i) This work is licensed under a Creative Commons Attribution 4.0 International License.

Read Full License 
1 Development of mycelium materials incubating Pleurotus ostreatus fungi with

2 different substrates composed of poplar sawdust and cottonseed hull

3 Rong Ding ${ }^{1}$, Xinyu Yang ${ }^{1}$, Liucheng Peng ${ }^{1}$, Jing Xie Xi, $^{1,3,4}$, *, Chenwei Chen ${ }^{1,2,3,4, *}$

$4{ }^{\text {a }}$ College of Food Science and Technology, Shanghai Ocean University, Shanghai, 201306, China

5 b Shanghai Professional Technology Service Platform on Cold Chain Equipment Performance and

6 Energy Saving, Evaluation, Shanghai, 201306, China

$7 \quad{ }^{\mathrm{c}}$ Shanghai Engineering Research Center of Aquatic-Product Processing \& Preservation, Shanghai,

8 201306, China

$9 \quad{ }^{\mathrm{d}}$ National Experimental Teaching Demonstration Center for Food Science and Engineering

10 (Shanghai Ocean University), Shanghai, 201306, China

Correspondence to: Chenwei Chen (cwchen@shou.edu.cn) and Jing Xie (jxie@shou.edu.cn)

Abstract: The mycelium materials incubating Pleurotus ostreatus fungi based on different substrate compositions were developed, the main components of which were poplar sawdust and cottonseed hull in different proportions. The hyphae on the surface of the samples become dense from appearance due to the addition of cottonseed hull. The Fourier Transforms Infrared analysis revealed that the cellulose, hemicellulose and lignin in substrates of all samples were degraded in different degrees owing to utilization by hyphae growth. The morphology and mechanical properties of the mycelial materials changed as the substrate compositions varied. The difference of properties among all mycelium materials was mainly attributed to the growth of mycelium and different substrate compositions. And the mycelium material (the ratio of poplar sawdust to cottonseed hull was 1) exhibited highest strength and lowest compression set, indicating that its size recovery capability was best. In comparison, the substrate of this material was more favorable to the growth of the mycelium and it showed optimal comprehensive performance among all samples. The mycelium material showed good potentiality for packaging application.

Keywords: Mycelium, Mycelium material, Pleurotus ostreatus fungi, substrate

\section{Introduction}

With the development of the global commodity economy, a large number of plastic cushion packaging materials were widely used to protect commodities during transportation, storage and distribution, such as expanded polystyrene (EPS) and polyurethane (PU), owing to their low density, moisture resistance and excellent cushioning properties (Chen et al., 2015). However, these packaging materials are basically petroleum-based materials of organic synthetic polymers, which have caused serious environmental pollution due to their abuse and non-biodegradability, which was one of the environmental problems that need to be solved urgently (Singh et al., 2016). Therefore, many scholars had turned their attention to natural origin polymers, such as cellulose foam (Li et al., 2018; Li et al., 2017; Obradovic et al., 2017), starch foam (Iriani et al., 2015; Engel et al., 2019) and biomass materials (Ajala et al., 2021;Song et al., 2019). Using woody plants, grasses, vines and their processing residues and wastes as raw materials, biomass materials were produced as new materials with excellent performance through physics, chemistry and biology technologies (Narayan, 2006). In recent years, mycelium materials were initiated by incubating saprophytic fungi with plant waste to fabricate bio-degradable porous materials. As a new type of biomass material, the mycelium material was considered to be a new alternative to petroleum-based materials (Melorose et al., 2015). It was a field with little attention but full of 
research potential (Fratzl and Barth, 2009). The mycelium material was obtained by inoculating saprophytic fungi on agricultural wastes rich in cellulose and lignin (López Nava et al., 2016), and the fungal vegetative hyphae secrete cellulase, lignin peroxidase and laccase, which were used to degrade cellulose, hemicellulose and lignin in agricultural wastes such as wood chips, straw and cottonseed hull to obtain vegetative growth substances (Hoa and Wang, 2015; Jiang et al., 2016). During this process, the mycelium penetrated into the matrix and continuously grew staggered to form a three-dimensional network structure that wrapped the matrix (Bonfante and Genre, 2010). After the growth of the mycelium was completed, it was dried to obtain the mycelium material. Considering the capacity to consume and utilize agricultural waste, the fast growing rate of mycelium, its biodegradability and reusability as fertilizer after being discarded, its unique mechanical and aesthetic properties (Attias et al., 2020), which can fully meet the requirements of sustainable development (Teixeira et al., 2018).

The performances of mycelium material were affected by many factors (Appels et al., 2019), mainly including fungal species, substrates composition and fabrication process (Elsacker et al., 2019). The selected fungal species evidently affected mycelium colonization and the physical-mechanical properties of the formed material (Attias et al., 2020). In the existing researches, Ganoderma lucidum and Pleurotus ostreatus were found to be the most commonly used. And Pleurotus ostreatus hyphae had higher Young's modulus and better rigidity comparing with Ganoderma lucidum. In addition, the type and size of substrate particles would directly influence various properties of the final mycelium material (Attias et al., 2020). The characteristics of mycelium changed with little changes in the substrate composition. For example, adding glucose to the standard medium was more easily absorbed by the mycelium than cellulose And it promoted the biosynthesis of lipids and proteins in the mycelium that acted as a "plasticizer", thereby improving the ductility of the mycelium (Haneef et al., 2017). It was also reported that the incorporation of glucose would increase the porous structure of the mycelium and the addition of lignin made the hyphae with slender characteristic (Antinori et al., 2020). Similar to mycelia cultured on culture medium, the properties of mycelia cultured by different agricultural by-products were also different. For example, the compressive strength of mycelium materials cultured on sawdust and bagasse was higher than that of pure sawdust and bagasse (Joshi et al., 2020), the introduction of natural fibers in the substrate with special treatment can improve the mechanical properties of materials (Jiang et al., 2019). Fabrication process was also an important factor to affect the properties of mycelium material. According to reports, the final performance of the material increased with the increase of the hot pressing temperature (Liu et al., 2019). It was precisely because of the many possibilities of mycelium materials that it had become a popular choice for replacing some petroleum-based materials.

The purpose of this study was to develop the mycelium materials using Pleurotus ostreatus mycelium based on different substrates composition, which was mainly composed of poplar sawdust and cottonseed hull. By comparing morphological characteristic, physical property, chemical composition, thermal degradation and mechanical properties of the mycelium materials, the effect of substrates composition on the properties of the materials were investigated.

\section{Materials and Methods}

\subsection{Materials}

Pleurotus ostreatus (ACCC52204) came from the Tianda Institute of Edible Fungi of Jiangsu Province and was stored at $4{ }^{\circ} \mathrm{C}$. Poplar sawdust was purchased from Huifeng straw agricultural 
products processing. Cottonseed hull was purchased from Texas Edible Fungus Research Institute.

\subsection{Preparation of mycelium materials}

Table 1 showed different substrate compositions for preparing mycelium materials. The culture medium for inoculating strains was prepared according to the ratio in Table 1 . The dry substrate was mixed with distilled water uniformly at a ratio (w/w) of $1: 1.3$. Then, the culture medium was sterilized at $121.3^{\circ} \mathrm{C}$ and $103.4 \mathrm{kPa}$ for 30 minutes. After cooling to room temperature, the culture medium with same quality was poured into a square Petri dish of $100 \times 100 \times 20 \mathrm{~mm}$ (length $\times$ width $\times$ height) under aseptic conditions. Pleurotus ostreatus strains $(3 \%, \mathrm{w} / \mathrm{w})$ were inoculated in the culture medium, and then the inoculated samples were cultured in a constant temperature and humidity incubator at $25^{\circ} \mathrm{C}$ and $90 \%$ relative humidity (RH) for 14 days. Finally, these samples were dried at $60^{\circ} \mathrm{C}$ for 48 hours to obtain the mycelium materials (Tacer-Caba et al., 2020).

Table1 Substrate composition of mycelium materials

\begin{tabular}{ccc}
\hline Sample & Sawdust $(w / w)$ & Cottonseed hull $(w / w)$ \\
\hline $\mathrm{S}_{10} \mathrm{C}_{0}$ & $100 \%$ & $0 \%$ \\
$\mathrm{~S}_{9} \mathrm{C}_{1}$ & $90 \%$ & $10 \%$ \\
$\mathrm{~S}_{7} \mathrm{C}_{3}$ & $70 \%$ & $30 \%$ \\
$\mathrm{~S}_{5} \mathrm{C}_{5}$ & $50 \%$ & $50 \%$ \\
$\mathrm{~S}_{3} \mathrm{C}_{7}$ & $30 \%$ & $70 \%$ \\
$\mathrm{~S}_{1} \mathrm{C}_{9}$ & $10 \%$ & $90 \%$ \\
$\mathrm{~S}_{0} \mathrm{C}_{10}$ & $0 \%$ & $100 \%$ \\
\hline
\end{tabular}

\subsection{Scanning electron microscope (SEM)}

The microstructures of all samples were analyzed by SEM using SU-5000 (Hitachi Co. Ltd, Matsuda, Japan). Before testing, the samples were cut into size of $5 \mathrm{~mm} \times 5 \mathrm{~mm}$ in liquid nitrogen. After sputtering gold plating, the measurement was performed using SU-5000 at an accelerating voltage of $5 \mathrm{kv}$.

\subsection{Density}

The sample was placed in an environment of $25^{\circ} \mathrm{C}$ and $50 \% \mathrm{RH}$ to complete the measurement. The density of the materials was calculated by the following formula.

$d=\frac{m}{v}$

where $\mathrm{d}$ is the density in $\mathrm{g} / \mathrm{cm}^{3}, m$ is the mass of the sample material in $\mathrm{g}$, and $v$ is the sample volume in $\mathrm{cm}^{3}$

\subsection{Color}

A Konica Minolta CR-400 Chroma meter (Minolta Co. Ltd, Tokyo, Japan) was used to measure the color of the material surface, where $\mathrm{L}^{*}$ represents brightness, $\mathrm{a}^{*}$ represents red and green, and $b^{*}$ represents yellow and blue. The white standard plate $\left(\mathrm{L}^{*}=94.28, \mathrm{a}^{*}=-1.39, \mathrm{~b}^{*}=5.22\right)$ was used as a comparison. The total color difference $(\triangle \mathrm{E})$ was calculated using formula as follows:

$\Delta E^{*}=\left[\left(\Delta L^{*}\right)^{2}+\left(\Delta a^{*}\right)^{2}+\left(\Delta b^{*}\right)^{2}\right]^{0.5}$ 


\subsection{Fourier transforms infrared (FTIR) spectroscopy analysis}

The Fourier infrared spectrophotometer Spotlight 400 (PerkinElmer, Waltham, Massachusetts, USA) was used for identification of the materials in the range of $4250 \mathrm{~cm}^{-1}$ to $500 \mathrm{~cm}^{-1}$ with a resolution of $4 \mathrm{~cm}^{-1}$, and repeated scanning 32 times.

\subsection{Thermogravimetric analysis (TGA)}

The TGA was performed on a NETZSCH TG 209 F1 thermal analyzer (NETZSCH Scientific Instruments Trading (Shanghai) Co., Ltd., Germany) at a heating rate of $10^{\circ} \mathrm{C} / \mathrm{min}$ under a nitrogen atmosphere from $30^{\circ} \mathrm{C}$ to $800^{\circ} \mathrm{C}$. The weight of the samples was approximately $5-10 \mathrm{mg}$.

\subsection{Static compression}

An electronic universal testing machine DDL-100 (Changchun Institute of Mechanical Science Co., Ltd., Changchun, China) was used for static compression test. The samples with $100 \times 100 \times 20 \mathrm{~mm}$ (length $\times$ width $\times$ height) were placed on the platform of the machine for compressing with a pressure plate at a speed of $12 \mathrm{~mm} / \mathrm{min}$. The stress-strain curves of the materials were obtained from these measurements.

\subsection{Compression set (CS)}

The CS was tested on the electronic universal testing machine DCP-KY3000 (Sichuan Changjiang Papermaking Instrument Co., Ltd., Sichuan, China). The samples were placed on the platform of the machine for compressing with a pressure plate at a speed of $12 \mathrm{~mm} / \mathrm{min}$. The compression was $20 \%$ of the sample thickness. After 15 minutes of compression, the pressure was released and the thickness was measured. The CS of the materials were calculated by the following formula.

$C S=\frac{d_{0}-d_{1}}{d_{1}} \times 100 \%$

where $C S$ is the Compression set in $\%, d_{0}$ is the initial thickness of the sample in mm and $d_{1}$ is the final thickness of the sample in $\mathrm{mm}$.

\subsection{Statistical analysis}

The statistical analysis of the data was performed through ANOVA using SPSS software (Version 20.0, Inc., Chicago, IL, USA). The differences among mean values were evaluated by Duncan's multiple range tests. Significance level was defined at $5 \%$. The data were represented as means \pm standard deviation.

\section{Results and discussion}

\subsection{Morphological analysis}

The photos and the SEM image of mycelium materials made of different matrix components were shown in Fig.1. As shown in the photos, white hyphae can be observed on the surface of all samples and the hyphae on the surface of the samples become dense with the increase content of cottonseed hull. The hyphae on the surface of $\mathrm{S}_{10} \mathrm{C}_{0}$ was relative sparse, which can't wrap the culture medium well and the internal hyphae had poor adhesion. The SEM result showed that the mycelia of $\mathrm{S}_{10} \mathrm{C}_{0}$ were slender and it became thick as the content of cottonseed hull increased. It suggested that the internal adhesion of the material would increase compared with $\mathrm{S}_{10} \mathrm{C}_{0}$. This was attributed to that the mixture of cottonseed hull and sawdust was conducive to the growth of hyphae and a certain amount of cottonseed hull would promote the colonization of strains. On the 
one hand, cottonseed hull is a by-product of cotton and it contain more crude protein, crude fat and soluble sugar (Yu et al., 2020). On the other hand, the addition of cottonseed hull would reduce the $\mathrm{C} / \mathrm{N}$ ratio of culture medium, which was propitious to promote hypha growth better. However, the growth of $S_{1} C_{9}$ and $S_{0} C_{10}$ were weaker than $S_{7} C_{3}, S_{5} C_{5}$ and $S_{3} C_{7}$, which may be due to the existence of free gossypol in cottonseed hull and the increase of gossypol content affects the growth of hyphae using cottonseed hull. So, the growth of mycelium was closely correlated with the substrate composition. Similarly, Sisti (Sisti et al., 2021) uses different proportions of bran to verify the effect of the matrix on the surface morphology of the material. It was found that the width of the mycelium increased by up to $38 \%$ in the material with $30 \%$ wheat bran.

The SEM image at 5um scale in Fig. 1 showed the growth of hyphae attached to matrix particles. Mycelia decomposes and digests the matrix by its own enzyme, and the hypha was macroscopically wrapped around the matrix, just like glue bonding the matrix. It can be seen from the SEM image of 20um scale in Fig. 1 that the hyphae on the surface of mycelium material gradually change from the intersecting and winding three-dimensional network structure to the hyphal membrane structure, which were stacked layer by layer. This was similar to the SEM results of freeze-dried mushroom slices reported by Liuqing (Liuqing et al., 2018). It reflected that the surface layer of mycelium in the final material were similar to mushroom solid, which was one of the reasons for the soft elasticity of the material texture.
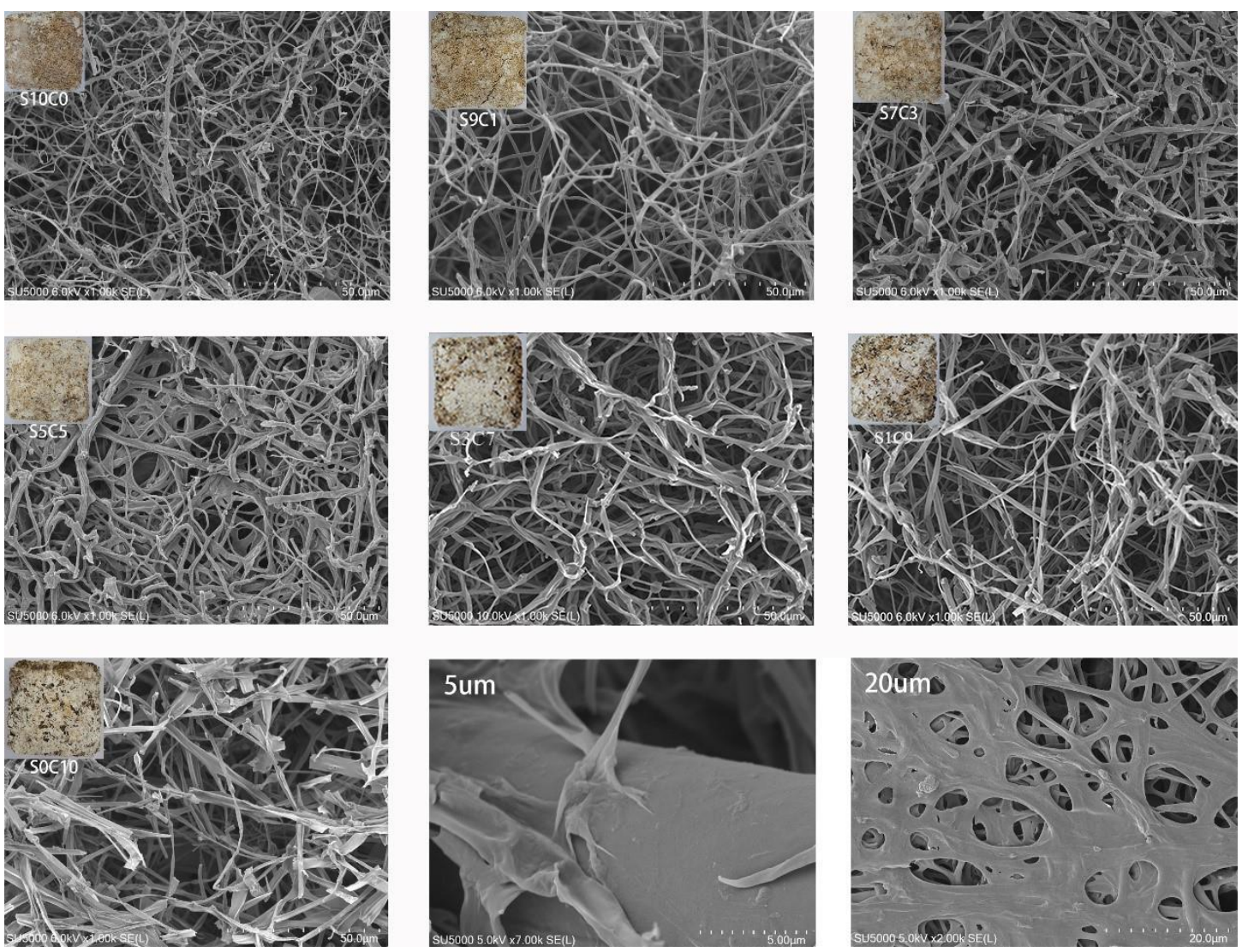

Fig. 1 Visual and scanning electron micrograph of the sample. $\mathrm{S}_{10} \mathrm{C} 0, \mathrm{~S}_{9} \mathrm{C}_{1}, \mathrm{~S}_{7} \mathrm{C}_{3}, \mathrm{~S}_{5} \mathrm{C}_{5}, \mathrm{~S}_{3} \mathrm{C}_{7}, \mathrm{~S}_{1} \mathrm{C}_{9}$, $\mathrm{S}_{0} \mathrm{C}_{10}$ eye view and scanning electron micrograph (50um); Growth image of hyphae attached to substrate particles at 5um; The phenomenon of "hyphae film" on the surface of the sample at the 20um. 


\subsection{Density and color}

Fig. 2 showed the density and surface color difference of all mycelium material samples. With the increase content of cottonseed hull, the density gradually increased, and the density of pure cottonseed hull sample $\left(\mathrm{S}_{0} \mathrm{C}_{10}\right)$ was the highest, which was attributed to the fact that the density of cottonseed hull material was higher than that of sawdust. The density of all samples ranged from 0.21 to $0.29 \mathrm{~g} / \mathrm{cm}^{3}$, which were comparable to the previous reported results that were in the range of 0.059 to $0.39 \mathrm{~g} / \mathrm{cm}^{3}$ (Jones et al., 2017; Appels et al., 2019). Compared with common packaging materials, the density of mycelium material was higher than EPS $\left(0.05 \mathrm{~g} / \mathrm{cm}^{3}\right)$ (Tacer-Caba et al., 2020) and Expandable Polyethylene (EPE) $\left(0.023-0.035 \mathrm{~g} / \mathrm{cm}^{3}\right)$, but lower than that of particleboard $\left(0.55-0.70 \mathrm{~g} / \mathrm{cm}^{3}\right)$ and medium density fiberboard $\left(0.50-1.00 \mathrm{~g} / \mathrm{cm}^{3}\right)$. It should be noted that there were many factors that affected the material density of mycelium, such as fungus species, substrate formula and process conditions.

The mycelium of Pleurotus ostreatus is white and the substrate is yellow-black. The surface of a well-grown sample would be covered with white mycelium. Therefore, the degree of mycelium colonization on the surface of the sample can be evaluated by the color parameters. The larger $L^{*}$ meant the surface of material was much whiter and brighter (Zhang et al., 2019). The reduced $\triangle \mathrm{E}$ indicated the color difference between the mycelium material and the standard whiteboard decreased. As cottonseed hull ratio increased, the $\mathrm{L}^{*}$ increased firstly and then reduced slightly, the $\triangle \mathrm{E}$ greatly decreased firstly and then slowly increased. The $\mathrm{S}_{5} \mathrm{C}_{5}$ exhibited highest $\mathrm{L}^{*}$ and lowest $\triangle \mathrm{E}$, which indicated that the hyphae grew most abundant on the surface of this material due to the increased addition of cottonseed hull. But the slightly increased $\triangle \mathrm{E}$ and decreased $\mathrm{L}^{*}$ showed that the high load cottonseed hull exceeded $50 \%$ would not conducive to hypha growth. The change trend of $b^{*}$ showed the same result. Because the surface color of the material was yellowish owing to the yellow-brown color of sawdust and cottonseed hull. The big $b^{*}$ reflected the poor growth of hyphae on the material. These results were also supported by the results observed in photos and SEM. 


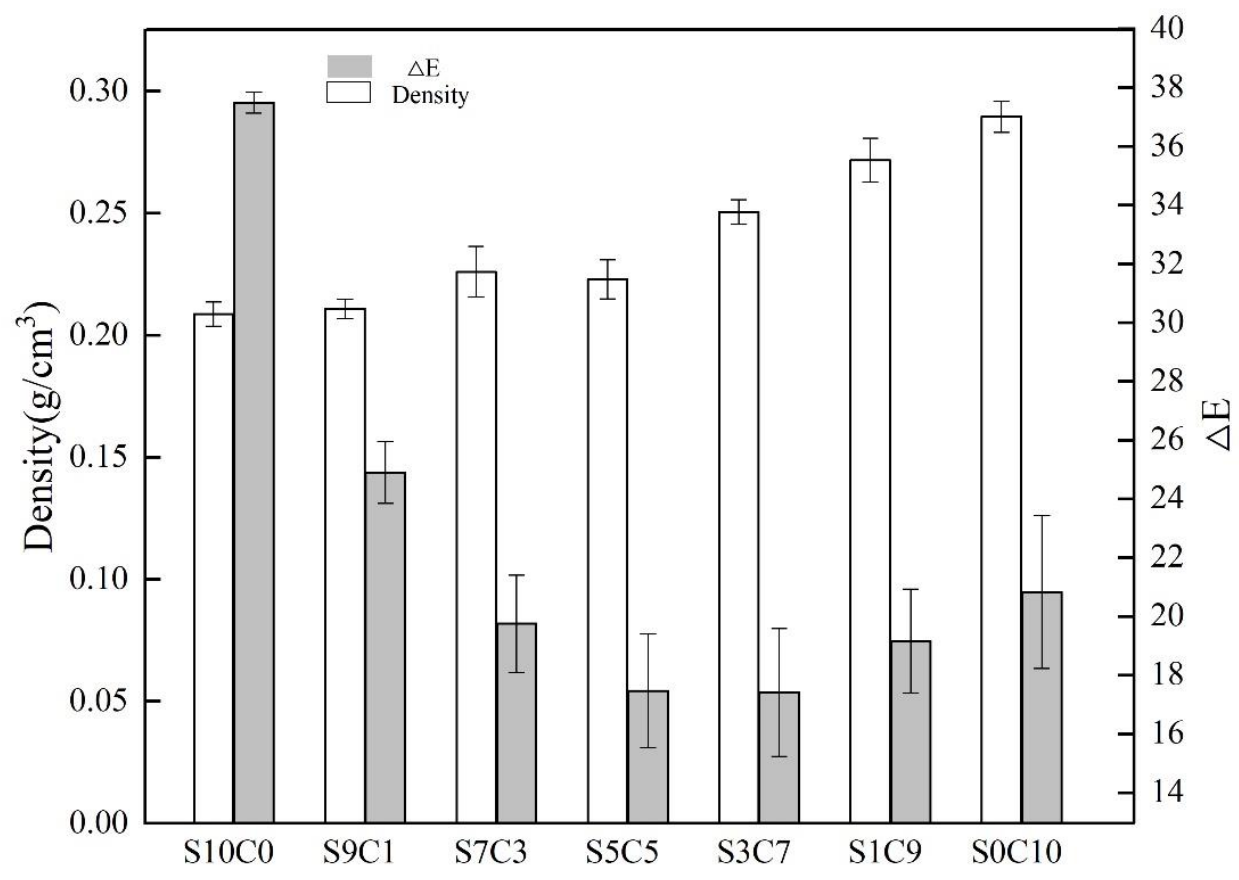

Fig. 2 Density and surface color difference of all mycelium materials

Table2 Colormetric parameters of all mycelium materials

\begin{tabular}{ccccc}
\hline Sample & $\mathrm{L}^{*}$ & $\mathrm{a}^{*}$ & $\mathrm{~b}^{*}$ & $\triangle \mathrm{E}$ \\
\hline $\mathrm{S}_{10} \mathrm{C}_{0}$ & $67.07 \pm 0.56 \mathrm{c}$ & $7.07 \pm 0.21 \mathrm{a}$ & $29.57 \pm 0.91 \mathrm{a}$ & $34.50 \pm 0.36 \mathrm{a}$ \\
$\mathrm{S}_{9} \mathrm{C}_{1}$ & $76.06 \pm 1.65 \mathrm{~b}$ & $3.40 \pm 0.42 \mathrm{~b}$ & $21.36 \pm 2.25 \mathrm{~b}$ & $24.90 \pm 1.06 \mathrm{~b}$ \\
$\mathrm{~S}_{7} \mathrm{C}_{3}$ & $78.96 \pm 0.83 \mathrm{ab}$ & $1.52 \pm 0.17 \mathrm{c}$ & $17.12 \pm 3.19 \mathrm{bc}$ & $19.75 \pm 1.66 \mathrm{c}$ \\
$\mathrm{S}_{5} \mathrm{C}_{5}$ & $79.99 \pm 0.67 \mathrm{a}$ & $1.64 \pm 0.64 \mathrm{c}$ & $14.65 \pm 2.61 \mathrm{c}$ & $17.46 \pm 1.94 \mathrm{c}$ \\
$\mathrm{S}_{3} \mathrm{~S}_{7}$ & $79.72 \pm 2.39 \mathrm{a}$ & $2.10 \pm 0.56 \mathrm{c}$ & $14.05 \pm 0.55 \mathrm{c}$ & $17.41 \pm 2.18 \mathrm{c}$ \\
$\mathrm{S}_{1} \mathrm{C}_{9}$ & $79.13 \pm 0.20 \mathrm{ab}$ & $2.33 \pm 0.44 \mathrm{c}$ & $16.17 \pm 2.97 \mathrm{bc}$ & $19.16 \pm 1.77 \mathrm{c}$ \\
$\mathrm{S}_{0} \mathrm{C}_{10}$ & $76.71 \pm 2.13 \mathrm{ab}$ & $1.79 \pm 0.44 \mathrm{c}$ & $15.74 \pm 3.01 \mathrm{bc}$ & $20.83 \pm 2.61 \mathrm{c}$ \\
\hline
\end{tabular}

\subsection{FTIR spectroscopy analysis}

Pleurotus ostreatus hyphae rely on secreting various enzymes to decompose organic substances such as cellulose, hemicellulose and lignin in sawdust and cottonseed hull to obtain nutrition. Therefore, the growth of hyphae can be reflected by infrared analysis of substrate after culture. Fig. 3 was the infrared spectrum of the substrate. Table 3 showed the distribution of infrared spectral bands of all sample substrates.

The infrared spectrum of $\mathrm{S}_{10} \mathrm{C}_{0}$ band was similar to that of poplar (Demcak et al., 2017), suggesting that $\mathrm{S}_{10} \mathrm{C}_{0}$ matrix was close to uncultured state. Compared with $\mathrm{S}_{10} \mathrm{C} 0$, the C-O deformation absorption peak $\left(1030 \mathrm{~cm}^{-1}\right)$ (Mohan et al., 2006) and the $\mathrm{C}-\mathrm{H}$ stretching vibration absorption peak $\left(1370 \mathrm{~cm}^{-1}\right)$ in the secondary alcohols and fatty ethers characterizing cellulose and hemicellulose in other samples were weakened to some extent, and the weakest absorption peaks appeared in $\mathrm{S}_{7} \mathrm{C}_{3}$ and $\mathrm{S}_{5} \mathrm{C}_{5}$. This indicated that cellulose and hemicellulose in the substrate were 
degraded and utilized by hyphae growth. And the absorption peak of $\mathrm{C}=\mathrm{O}$ stretching vibration $\left(1731 \mathrm{~cm}^{-1}\right)$ (Saetun et al., 2017) in the non-conjugated ketones and ester groups of hemicellulose was also obviously weakened. These results indicated that hyphae grew well with substrate in $\mathrm{S}_{7} \mathrm{C}_{3}$ and $\mathrm{S}_{5} \mathrm{C}_{5}$, and hemicellulose degraded more than cellulose. In addition, the methylene $\left(\mathrm{CH}_{2}\right)$ bending vibration absorption peak $\left(1454 \mathrm{~cm}^{-1}\right)$, lignin phenolic ether bond C-O stretching vibration $\left(1241 \mathrm{~cm}^{-1}\right)$ and carbonyl conjugated aryl ketone $\mathrm{C}=\mathrm{O}\left(1638 \mathrm{~cm}^{-1}\right)$ (Fungi, 2005) which characterized lignin weakened or even disappeared in other samples. The characteristic absorption peak $\left(1326 \mathrm{~cm}^{-1}\right)$ (Kubo and Kadla, 2005), which characterized the vibration of syringyl (S) and the condensation of guaiacyl $(\mathrm{G})$ and syringyl $(\mathrm{S})$, also weakened to varying degrees. It indicated that lignin in other samples were degraded and utilized by the growth of hyphae to varying degrees. To sum up, the FTIR results revealed that the cellulose, hemicellulose and lignin of other samples were degraded in different degrees comparing with $\mathrm{S}_{10} \mathrm{C}_{0}$. The colonization degree of mycelium in other samples were better than $\mathrm{S}_{10} \mathrm{C}_{0}$. In comparison, the substrate of $\mathrm{S}_{5} \mathrm{C}_{5}$ was more favorable to the growth of the mycelium.

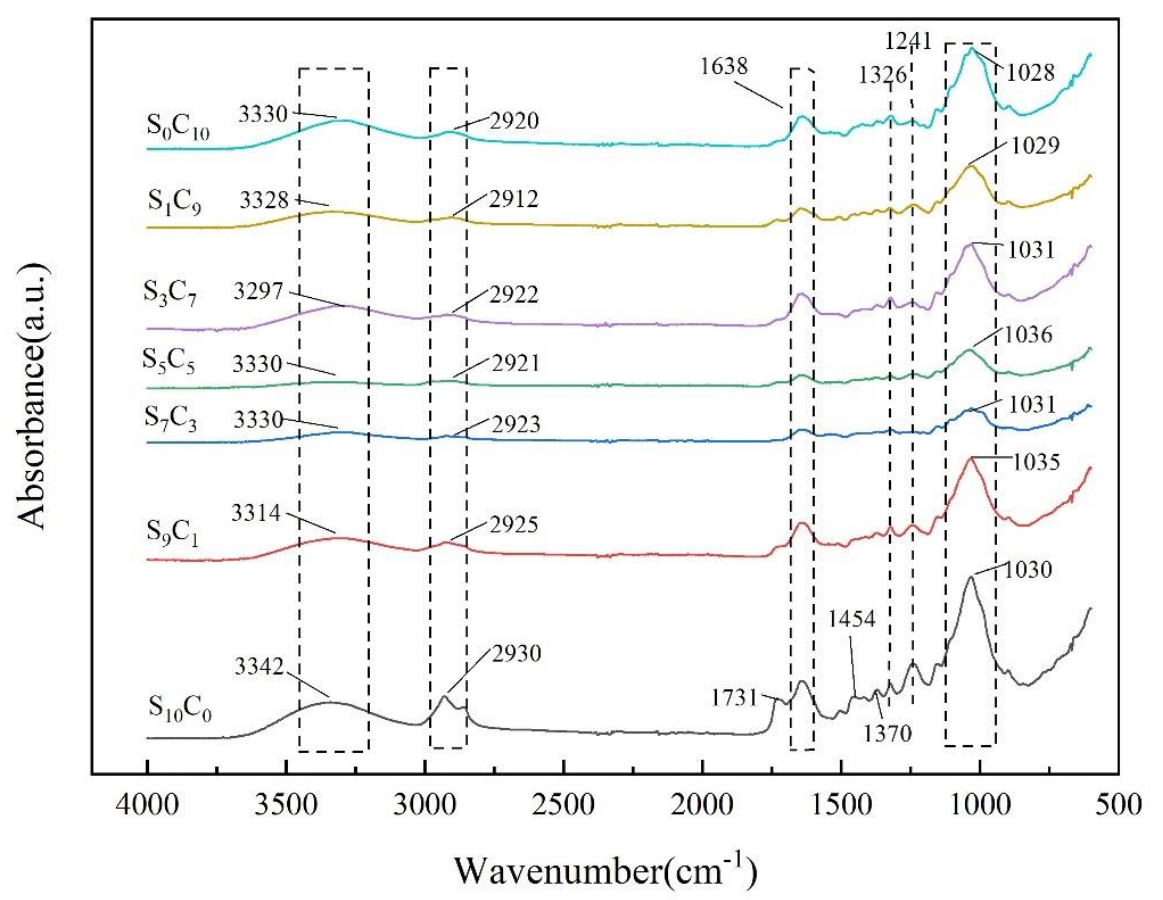

Fig. 3 Infrared spectrum of all mycelium materials

Table 3 Infrared spectrum characteristic peaks and their assignments of all mycelium materials

\begin{tabular}{|c|c|c|c|c|c|c|c|c|}
\hline \multirow{2}{*}{ Assignment } & \multicolumn{7}{|c|}{ Wavenumber $\left(\mathrm{cm}^{-1}\right)$} & \multirow{2}{*}{ Main contribution } \\
\hline & $\mathrm{S}_{10} \mathrm{C}_{0}$ & $\mathrm{~S}_{9} \mathrm{C}_{1}$ & $\mathrm{~S}_{7} \mathrm{C}_{3}$ & $\mathrm{~S}_{5} \mathrm{C}_{5}$ & $\mathrm{~S}_{3} \mathrm{C}_{7}$ & $\mathrm{~S}_{1} \mathrm{C}_{9}$ & $\mathrm{~S}_{0} \mathrm{C}_{10}$ & \\
\hline $\mathrm{O}-\mathrm{H}$ stretching & 3342 & 3314 & 3330 & 3330 & 3297 & 3328 & 3330 & Hydroxy \\
\hline $\begin{array}{l}\mathrm{C}-\mathrm{H} \text { asymmetric } \\
\text { stretching }\end{array}$ & 2930 & 2925 & 2923 & 2921 & 2922 & 2912 & 2920 & $\mathrm{CH}_{3}, \mathrm{CH}_{2}$ \\
\hline $\mathrm{C}=\mathrm{O}$ stretching & 1731 & 1723 & & & & 1729 & & $\begin{array}{c}\text { Non-conjugated ketones } \\
\text { and ester groups }\end{array}$ \\
\hline $\mathrm{C}=\mathrm{O}$ stretching & 1638 & 1638 & 1638 & 1638 & 1638 & 1638 & 1638 & $\begin{array}{c}\text { Conjugated aryl ketone of } \\
\text { lignin carbonyl groups }\end{array}$ \\
\hline
\end{tabular}




\begin{tabular}{|c|c|c|c|c|c|c|c|c|}
\hline $\mathrm{CH}_{2}$ bending & 1454 & 1454 & 1454 & 1454 & 1454 & 1454 & 1454 & Lignin \\
\hline $\mathrm{C}-\mathrm{H}$ stretching & 1370 & 1370 & & & 1370 & 1370 & 1370 & Cellulose and hemicellulose \\
\hline $\begin{array}{l}\text { Condensation of } \\
\text { guaiacyl and }\end{array}$ & & & & & & & & \\
\hline $\begin{array}{c}\text { syringyl; } \\
\text { syringyl and }\end{array}$ & 1326 & 1326 & & & 1326 & 1326 & 1326 & Guaiac and syringa \\
\hline $\mathrm{CH} 2$ bending & & & & & & & & \\
\hline $\begin{array}{l}\mathrm{C}-\mathrm{O}-\mathrm{C} \\
\text { stretching }\end{array}$ & 1240 & 1241 & 1243 & 1240 & 1242 & 1240 & 1240 & $\begin{array}{c}\text { Phenol-ether bonds of } \\
\text { lignin }\end{array}$ \\
\hline $\mathrm{C}-\mathrm{O}$ deformation & 1030 & 1035 & 1031 & 1036 & 1031 & 1029 & 1028 & $\begin{array}{c}\text { Secondary alcohols and } \\
\text { fatty ethers of cellulose and } \\
\text { hemicellulose }\end{array}$ \\
\hline
\end{tabular}

\subsection{Thermal stability}

The TGA curves of all samples were shown in Fig. 4. The mycelium material exhibited similar thermal degradation behavior. It can be determined that all samples showed four stages of quality loss. In the first stage, the mass loss temperature was between $30^{\circ} \mathrm{C}$ and $134^{\circ} \mathrm{C}$, which was mainly the loss of free water, adsorbed water and crystal water (Joseph et al., 2003). In the second stage, the temperature was between $230^{\circ} \mathrm{C}$ and $310^{\circ} \mathrm{C}$, which was mainly the decomposition of organic components such as polysaccharide, chitin, amino acids and lipids in hyphae. The temperature of the third stage occurs at $320^{\circ} \mathrm{C}-410^{\circ} \mathrm{C}$, which was attributed to the pyrolysis of cellulose and hemicelluloses (Yang et al., 2007). The second and third stages were the main stages in the thermal degradation process. The temperature in the fourth stage was $440^{\circ} \mathrm{C}-800^{\circ} \mathrm{C}$, owing to the pyrolysis of lignin, thermal degradation of sample residues and oxidative decomposition products. The thermal degradation curve of $\mathrm{S}_{10} \mathrm{C}_{0}$ was different from that of other samples in the range of $370^{\circ} \mathrm{C}-440^{\circ} \mathrm{C}$. It was speculated that the hyphae of $\mathrm{S}_{10} \mathrm{C}_{0}$ grew poorly, and the wood chip substrate still contained relative many lignin that had not been decomposed by the hyphae (Borsoi et al., 2013). 


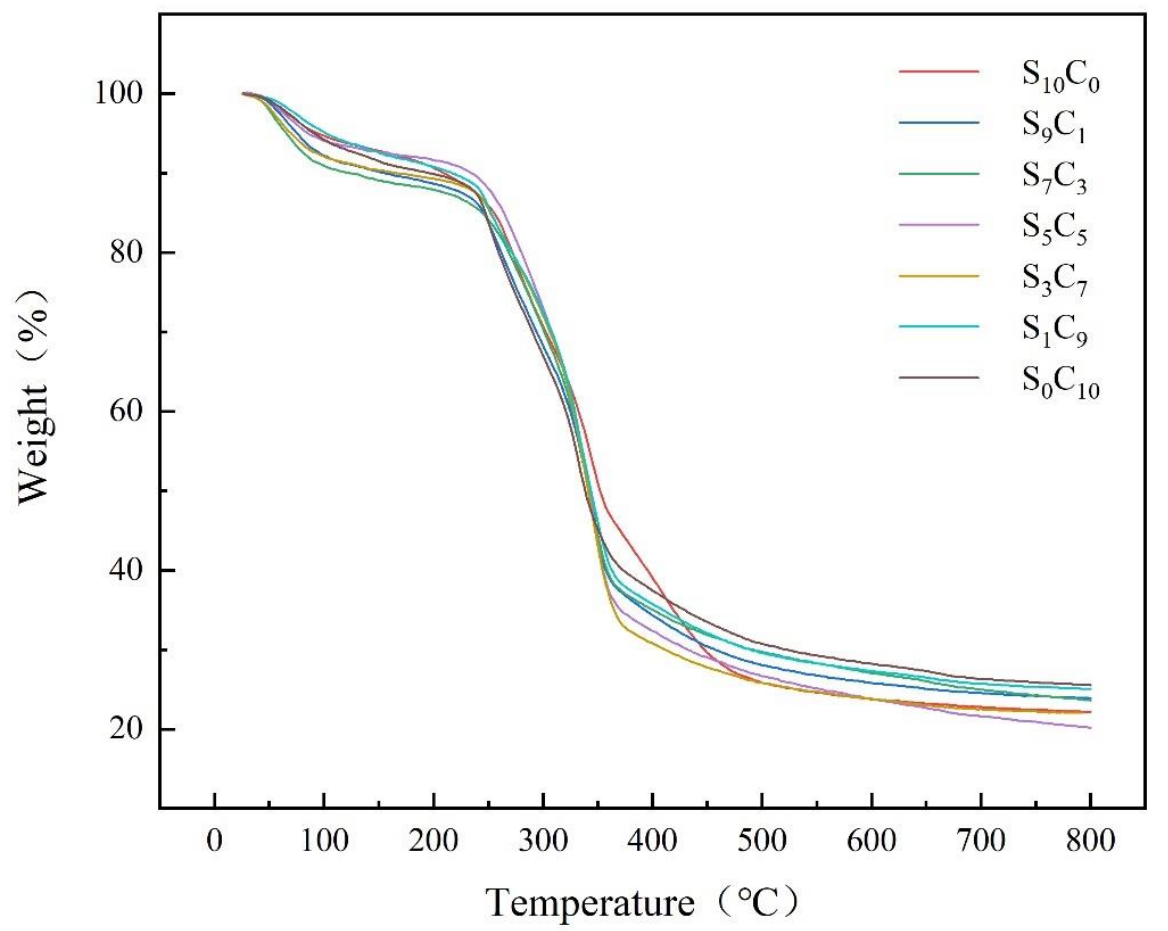

Fig. 4 The TGA curves of all mycelium materials

\subsection{Mechanical properties}

Fig. 5 and 6 were stress-strain curves and compression set (CS) results of all samples. It can be seen from Fig. 5 that the stress-strain curves of all samples were tangent type. It can be divided into two stages. When the strain was less than $0.16\left(S_{5} C_{5}\right.$ and $S_{3} C_{7}$ were 0.1$)$, the stress increased slightly. When the strain increased sequentially, the stress increased rapidly, the samples collapsed and was compacted. The $\mathrm{S}_{5} \mathrm{C}_{5}$ showed highest stress and strain level, followed by $\mathrm{S}_{3} \mathrm{C}_{7}$, which means that they can bear more stress under the same strain. The low stress and strain levels of $\mathrm{S}_{10} \mathrm{C}_{0}$ and $\mathrm{S}_{9} \mathrm{C}_{1}$ indicated that under the same stress, the material had greater strain. Combined with morphological analysis, the colonization level of $\mathrm{S}_{10} \mathrm{C}_{0}$ and $\mathrm{S}_{9} \mathrm{C}_{1}$ strains was poor, the ability of mycelium to bind to the matrix was weak, and the material collapses rapidly under low stress. This difference of mechanical property among all samples were mainly attributed to the growth of mycelium and different substrate. The mycelium material was viscoelastic material instead of single elasticity or viscosity. From the microscopic performance of materials, when the material was subjected to external force, on the one hand, the molecular chain deforms and after the external force was removed, the deformation recovers and shows elasticity; On the other hand, the molecular chain slips and after the external force was removed, the deformation can't be completely restored, resulting in permanent deformation, which shows viscosity.

The CS of all samples was presented in Fig. 6. It showed that the CS increased firstly and then decreased with increasing of cottonseed hull. The CS of $\mathrm{S}_{10} \mathrm{C}_{0}$ was $19.41 \%$, which was the largest of all samples. The larger CS meat the anti-compression deformation capacity and resilience of the material was worse. The CS value of $\mathrm{S}_{5} \mathrm{C}_{5}$ was significantly lower than that of the 
degree of colonization. The mycelium grew more flourishing, the cohesiveness of material was much stronger, leading to the enhanced resilience and size recovery capability of the material. It also suggested that the $\mathrm{S}_{5} \mathrm{C}_{5}$ material possessed best cushioning property among these samples.

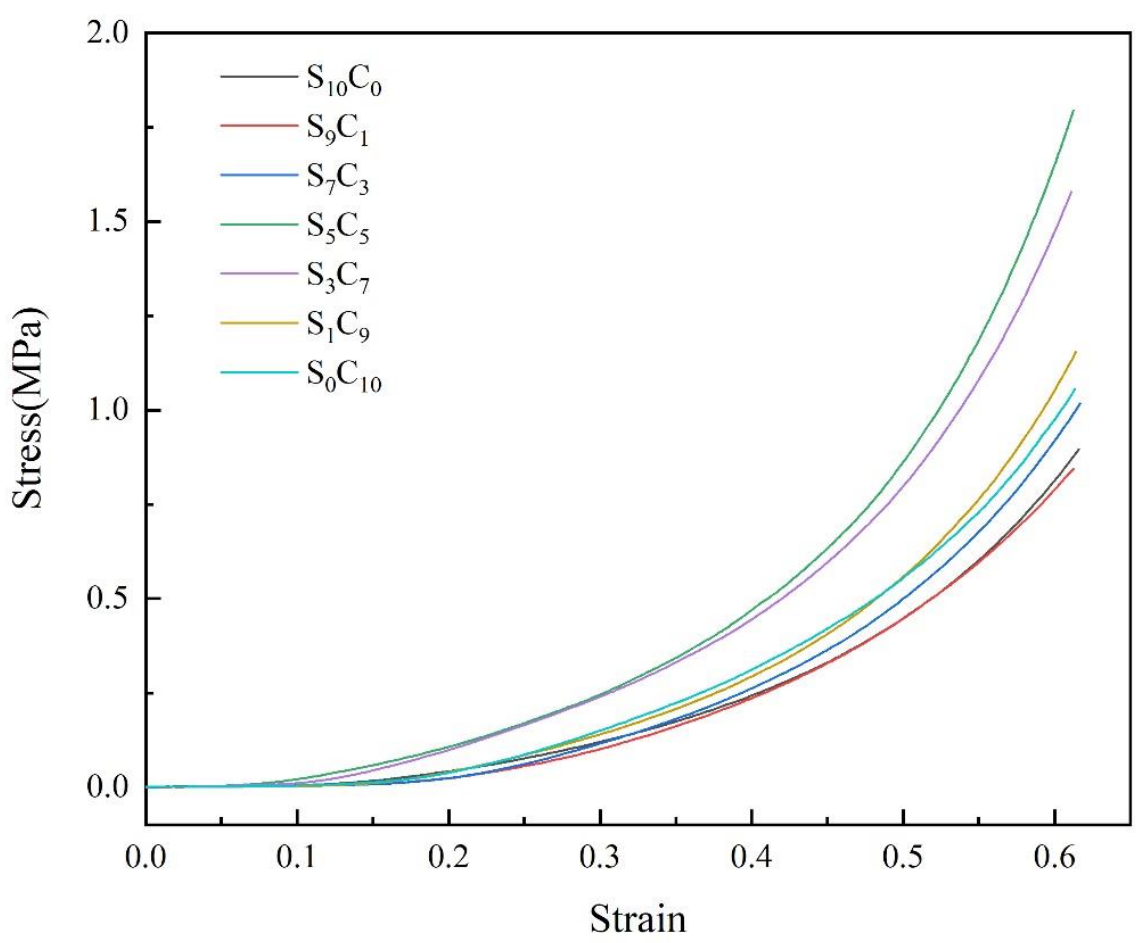




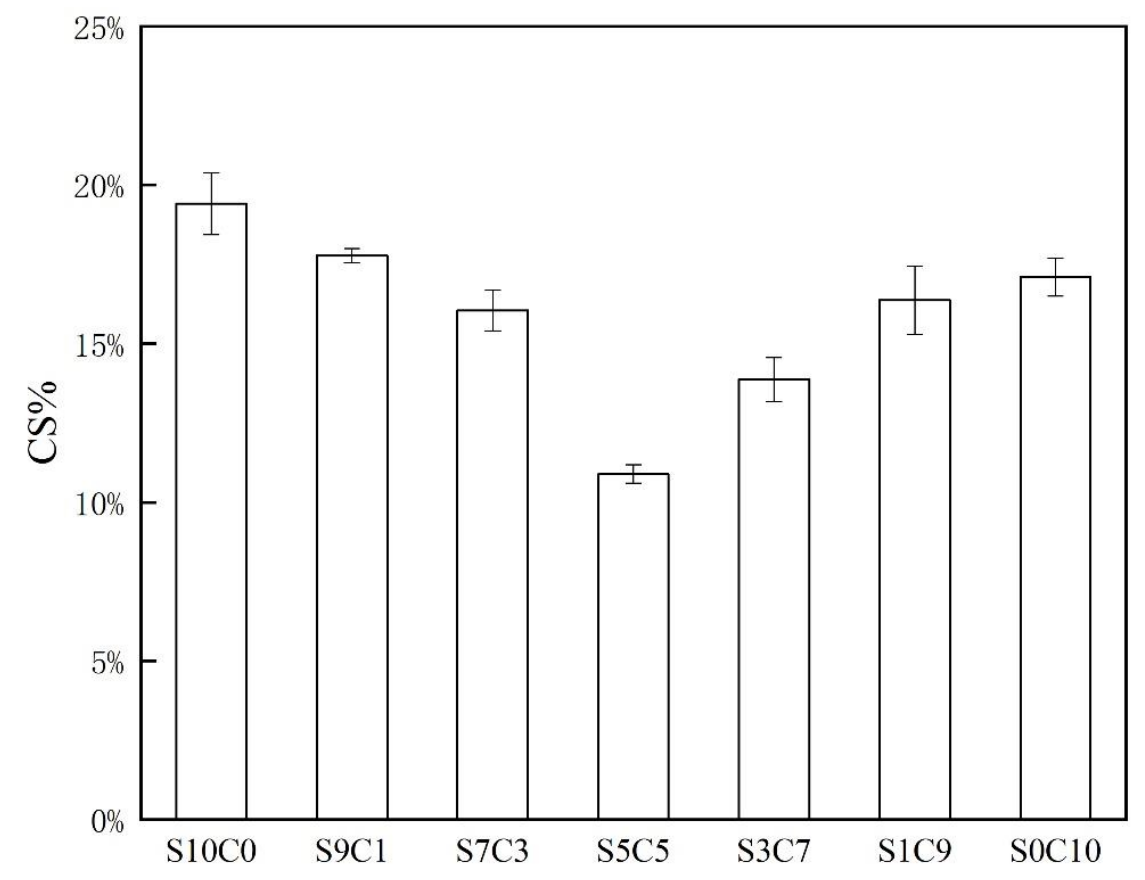

\section{Conclusions}

The mycelium materials were successfully developed by incubating Pleurotus ostreatus fungi with different substrates compositions, which were mainly composed of poplar sawdust and cottonseed hull in different ratios. The difference of properties among all samples was mainly attributed to the growth of mycelium and different substrate compositions. The hyphae on the surface of the samples become dense from appearance for the addition of cottonseed hull. The FTIR results revealed that the cellulose, hemicellulose, and lignin in substrates of all samples were degraded in different degrees due to utilization by hyphae growth. The hyphae of $\mathrm{S}_{5} \mathrm{C}_{5}$ grew most abundant on the surface of the material and the $\mathrm{S}_{5} \mathrm{C}_{5}$ sample exhibited the highest stress and strain level, followed by $\mathrm{S}_{3} \mathrm{C}_{7}$, which meant that they can bear more stress under the same strain. The CS of $\mathrm{S}_{5} \mathrm{C}_{5}$ was significantly lower than that of the other samples, indicating that its size recovery capability was best. In comparison, the substrate of $\mathrm{S}_{5} \mathrm{C}_{5}$ was more favorable to the growth of the mycelium and it showed optimal comprehensive performance among all samples. As a green material, the mycelium material showed good potentiality through different processing processes in the application of some areas, such as packaging materials, insulating materials and building materials. It is also a good topic and many issues are worth studying in the future.

\section{Supplementary Information}

\section{Abbreviations} microscope; FTIR: Fourier transforms infrared; TGA: Thermogravimetric analysis; CS: 
313 Not applicable.

\section{Authors' contributions}

$\mathrm{RD}$ was responsible for the preparation of mycelial materials and the writing of manuscripts. XY and LP involved material performance testing. JX and CC participated in the analysis, improvement and revision of the manuscript. All authors read and approved the final manuscript

\section{Funding}

This study was financed by the National Key R\&D Program of China (2018YFD0400701), Shanghai Municipal Science and Technology project (19DZ1207503) and Shanghai Municipal Science and Technology project to enhance the capabilities of the platform (19DZ2284000).

\section{Availability of data and materials}

Data will be made available upon request.

\section{Ethics approval and consent to participate}

Not applicable.

\section{Consent for publication}

Not applicable.

\section{Competing interests}

The authors declare that they have no competing interests.

\section{Author details}

$331{ }^{1}$ College of Food Science and Technology, Shanghai Ocean University, Shanghai, 201306, China

$332{ }^{2}$ Shanghai Professional Technology Service Platform on Cold Chain Equipment Performance and 333 Energy Saving, Evaluation, Shanghai, 201306, China

$334{ }^{3}$ Shanghai Engineering Research Center of Aquatic-Product Processing \& Preservation, Shanghai, 335 201306, China

$336{ }^{4}$ National Experimental Teaching Demonstration Center for Food Science and Engineering

337 (Shanghai Ocean University), Shanghai, 201306, China

\section{References}

Ajala, E.O., Ighalo, J.O., Ajala, M.A., Adeniyi, A.G., Ayanshola, A.M., 2021. Sugarcane bagasse: a biomass sufficiently applied for improving global energy, environment and economic sustainability. Bioresour. Bioprocess. 8. https://doi.org/10.1186/s40643-021-00440-z

Appels, F.V.W., Camere, S., Montalti, M., Karana, E., Jansen, K.M.B., Dijksterhuis, J., Krijgsheld, P., Wösten, H.A.B., 2019. Fabrication factors influencing mechanical, moisture- and water-related properties of mycelium-based composites. Mater. Des. 161, 64-71. https://doi.org/10.1016/j.matdes.2018.11.027

Attias, N., Danai, O., Abitbol, T., Tarazi, E., Ezov, N., Pereman, I., Grobman, Y.J., 2020. Mycelium bio-composites in industrial design and architecture: Comparative review and experimental analysis. J. Clean. Prod. 246. https://doi.org/10.1016/j.jclepro.2019.119037

Bonfante, P., Genre, A., 2010.Interactions in mycorrhizal symbiosis. Nat. Commun. 1, 1-11. https://doi.org/10.1038/ncomm 1046

Borsoi, C., Scienza, L.C., Zattera, A.J., 2013. Characterization of composites based on recycled expanded polystyrene reinforced with curaua fibers. J. Appl. Polym. Sci. 128, 653-659. https://doi.org/https://doi.org/10.1002/app.38236

Castro-Alves, V.C., Gomes, D., Menolli, N., Sforça, M.L., Nascimento, J.R.O. do, 2017. 
Characterization and immunomodulatory effects of glucans from Pleurotus albidus, a promising species of mushroom for farming and biomass production. Int. J. Biol. Macromol. 95, 215-223. https://doi.org/https://doi.org/10.1016/j.ijbiomac.2016.11.059

Chen, W., Hao, H., Hughes, D., Shi, Y., Cui, J., Li, Z.X., 2015. Static and dynamic mechanical properties of expanded polystyrene. Mater. Des. 69, 170-180. https://doi.org/10.1016/j.matdes.2014.12.024

Demcak, S., Balintova, M., Hurakova, M., Frontasyeva, M. V., Zinicovscaia, I., Yushin, N., 2017. Utilization of poplar wood sawdust for heavy metals removal from model solutions. Nov. Biotechnol. Chim. 16, 26-31. https://doi.org/10.1515/nbec-2017-0004

Elsacker, E., Vandelook, S., Brancart, J., Peeters, E., De Laet, L., 2019. Mechanical, physical and chemical characterisation of mycelium-based composites with different types of lignocellulosic substrates. PLoS One 14(7), e0213954. https://doi.org/10.1371/journal.pone.0213954

Engel, J.B., Ambrosi, A., Tessaro, I.C., 2019. Development of biodegradable starch-based foams incorporated with grape stalks for food packaging. Carbohydr. Polym. 225, 115234. https://doi.org/10.1016/j.carbpol.2019.115234

Fratzl, P., Barth, F.G., 2009. Biomaterial systems for mechanosensing and actuation.Nature 462, 442-448. https://doi.org/10.1038/nature08603

Fungi, R., 2005. FTIR Analysis on Function Groups of David Poplar Wood and Lignin Degraded by 6 Species of Wood White 2 Rot Fungi. Forestry 0-4.

Haneef, M., Ceseracciu, L., Canale, C., Bayer, I.S., Heredia-Guerrero, J.A., Athanassiou, A., 2017. Advanced Materials from Fungal Mycelium: Fabrication and Tuning of Physical Properties. Sci. Rep. 7, 1-11. https://doi.org/10.1038/srep4129Hoa, H.T., Wang, C.L., 2015. The Effects of Temperature and Nutritional Conditions on Mycelium Growth of Two Oyster Mushrooms (Pleurotus ostreatus and Pleurotus cystidiosus). Mycobiology 43, 14-23. https://doi.org/10.5941/MYCO.2015.43.1.14

Huang, Y., Yang, J., Chen, L., Zhang, L., 2018. Chitin Nanofibrils to Stabilize Long-Life Pickering Foams and Their Application for Lightweight Porous Materials. ACS Sustain. Chem. Eng. 6, 10552-10561. https://doi.org/10.1021/acssuschemeng.8b01883

Iriani, E.S., Irawadi, T.T., Sunarti, T.C., Richana, N., Yuliasih, I., 2015. Effect of Corn Hominy and Polyvinyl Alcohol on Mechanical Properties of Cassava Starch-Baked Foam. Polym. Plast. Technol. Eng. 54, 282-289. https://doi.org/10.1080/03602559.2014.977423

Jiang, L., Walczyk, D., McIntyre, G., Bucinell, R., Li, B., 2019. Bioresin infused then cured mycelium-based sandwich-structure biocomposites: Resin transfer molding (RTM) process, flexural properties, and simulation. J. Clean. Prod. 207, 123-135. https://doi.org/10.1016/j.jclepro.2018.09.255

Jiang, L., Walczyk, D., McIntyre, G., Chan, W.K., 2016. Cost modeling and optimization of a manufacturing system for mycelium-based biocomposite parts. J. Manuf. Syst. 41, 8-20. https://doi.org/https://doi.org/10.1016/j.jmsy.2016.07.004

Jiao, L., Xu, G., Wang, Q., Xu, Q., Sun, J., 2012. Thermochimica Acta Kinetics and volatile products of thermal degradation of building insulation materials. Thermochim. Acta 547, 120-125. https://doi.org/10.1016/j.tca.2012.07.020

Jones, M., Huynh, T., Dekiwadia, C., Daver, F., John, S., 2017. Mycelium Composites: A Review of Engineering Characteristics and Growth Kinetics. J. Bionanoscience 11, 241-257. https://doi.org/10.1166/jbns.2017.1440 
Joseph, P. V, Joseph, K., Thomas, S., Pillai, C.K.S., Prasad, V.S., Groeninckx, G., Sarkissova, M., 2003. The thermal and crystallisation studies of short sisal fibre reinforced polypropylene composites. Compos. Part A Appl. Sci. Manuf. 34, 253-266. https://doi.org/https://doi.org/10.1016/S1359-835X(02)00185-9

Kalia, S., Dufresne, A., Cherian, B.M., Kaith, B.S., Avérous, L., Njuguna, J., Nassiopoulos, E., 2011. Cellulose-Based Bio- and Nanocomposites: A Review. Int. J. Polym. Sci. 2011, 837875. https://doi.org/10.1155/2011/837875

Kubo, S., Kadla, J.F., 2005. Hydrogen Bonding in Lignin: A Fourier Transform Infrared Model Compound Study. Biomacromolecules 6, 2815-2821. https://doi.org/10.1021/bm050288q

Li, J., Cheng, R., Xiu, H., Zhang, M., Liu, Q., Song, T., Dong, H., Yao, B., Zhang, X., Kozliak, E., Ji, Y., 2018. Pore structure and pertinent physical properties of nanofibrillated cellulose (NFC)-based foam materials. Carbohydr. Polym. 201, 141-150. https://doi.org/10.1016/j.carbpol.2018.08.008

Liu, R., Long, L., Sheng, Y., Xu, J., Qiu, H., Li, X., Wang, Y., Wu, H., 2019. Preparation of a kind of novel sustainable mycelium/cotton stalk composites and effects of pressing temperature on the properties. Ind. Crops Prod. 141, 111732. https://doi.org/10.1016/j.indcrop.2019.111732

Li, R., Du, J., Zheng, Y., Wen, Y., Zhang, X., Yang, W., Lue, A., Zhang, L., 2017. Ultra-lightweight cellulose foam material: preparation and properties. Cellulose 24, 1417-1426. https://doi.org/10.1007/s10570-017-1196-y

Liuqing, W., Qiuhui, H., Fei, P., Alfred Mugambi, M., Wenjian, Y., 2018. Influence of different storage conditions on physical and sensory properties of freeze-dried Agaricus bisporus slices. Lwt 97, 164-171. https://doi.org/https://doi.org/10.1016/j.lwt.2018.06.052

López Nava, J.A., Méndez González, J., Ruelas Chacón, X., Nájera Luna, J.A., 2016. Assessment of Edible Fungi and Films Bio-Based Material Simulating Expanded Polystyrene. Mater. Manuf. Process. 31, 1085-1090. https://doi.org/10.1080/10426914.2015.1070420

Melorose, J., Perroy, R., Careas, S., 2015. Life, The Science of Biology, 9th ed, Statewide Agricultural Land Use Baseline 2015. Sinauer Associates. https://doi.org/10.1017/CBO9781107415324.004

Mohan, D., Pittman, C.U., Steele, P.H., 2006. Pyrolysis of Wood/Biomass for Bio-oil: A Critical Review. Energy \& Fuels 20, 848-889. https://doi.org/10.1021/ef0502397

Narayan, R., 2006. Biobased and biodegradable polymer materials: Rationale, drivers, and technology exemplars. ACS Symp. Ser. 939, 282-306. https://doi.org/10.1021/bk-2006-0939.ch018

Obradovic, J., Voutilainen, M., Virtanen, P., Lassila, L., Fardim, P., 2017. Cellulose fibre-reinforced biofoam for structural applications. Materials (Basel). 10, 1-10. https://doi.org/10.3390/ma10060619

Saetun, V., Chiachun, C., Riyajan, S.-A., Kaewtatip, K., 2017. Green composites based on thermoplastic starch and rubber wood sawdust. Polym. Compos. 38, 1063-1069. https://doi.org/https://doi.org/10.1002/pc.23669

Singh, M., Ohji, T., Asthana, R, 2016. Chapter 1 - Green and Sustainable Manufacturing of Advanced Materials_-Progress and Prospects, in: Singh, M., Ohji, T., Asthana, Rajiv (Eds.), Green and Sustainable Manufacturing of Advanced Material. Elsevier, Oxford, pp. 3-10. https://doi.org/https://doi.org/10.1016/B978-0-12-411497-5.00001-1

Sisti, L., Gioia, C., Totaro, G., Verstichel, S., Cartabia, M., Camere, S., Celli, A., 2021. Valorization of wheat bran agro-industrial byproduct as an upgrading filler for mycelium-based composite materials. Ind. Crops Prod. 170, 113742. https://doi.org/10.1016/j.indcrop.2021.113742 
Song, K., Zhu, X., Zhu, W., Li, X., 2019. Preparation and characterization of cellulose nanocrystal extracted from Calotropis procera biomass. Bioresour. Bioprocess. 6. https://doi.org/10.1186/s40643-019-0279-z

Tacer-Caba, Z., Varis, J.J., Lankinen, P., Mikkonen, K.S., 2020. Comparison of novel fungal mycelia strains and sustainable growth substrates to produce humidity-resistant biocomposites. Mater. Des. 192. https://doi.org/10.1016/j.matdes.2020.108728

Teixeira, J.L., Matos, M.P., Nascimento, B.L., Griza, S., Holanda, F.S.R., Marino, R.H., 2018. Production and mechanical evaluation of biodegradable composites by white rot fungi. Ciência e Agrotecnologia 42, 676-684.

Yang, H., Yan, R., Chen, H., Lee, D.H., Zheng, C., 2007. Characteristics of hemicellulose, cellulose and lignin pyrolysis. Fuel 86, 1781-1788. https://doi.org/10.1016/j.fuel.2006.12.013

Yu, J., Yang, H.M., Wan, X.L., Chen, Y.J., Yang, Z., Liu, W.F., Liang, Y.Q., Wang, Z.Y., 2020. Effects of cottonseed meal on slaughter performance, meat quality, and meat chemical composition in Jiangnan White goslings. Poult. Sci. 99, 207-213. https://doi.org/10.3382/ps/pez451

Zhang, L., Liu, Z., Wang, X., Dong, S., Sun, Y., Zhao, Z., 2019. The properties of chitosan/zein blend film and effect of film on quality of mushroom (Agaricus bisporus). Postharvest Biol. Technol. 155, 47-56. https://doi.org/https://doi.org/10.1016/j.postharvbio.2019.05.013 


\section{Supplementary Files}

This is a list of supplementary files associated with this preprint. Click to download.

- renamed81bfb.jpg 